\title{
Grounding the Aerial: The Observer's View in Digital Visualisation for Built Heritage
}

\author{
Kieran Baxter \\ Duncan of Jordanstone College of Art and Design \\ University of Dundee \\ Visual Research Centre, DCA,152 Nethergate, \\ Dundee, DD1 4DY \\ k.a.baxter@dundee.ac.uk
}

\begin{abstract}
The ways in which heritage sites are commonly represented - plans, aerial photographs and computer models - have been criticised for their tendency to elevate the viewer to a disembodied perspective that is removed from lived experience. This paper explores the disparity between the totalising tendency of visualisation techniques on one hand, and the need to consider the importance of human experience within built heritage on the other. Following on from existing work along the boundaries of art and archaeology, it is considered that creative practice - with its ability to incorporate emotional and experiential content into visual outcomes - can make a valuable contribution to this area.
\end{abstract}

Digital visualisation. Virtual reality. Embodied experience. Aerial photography. Heritage. Archaeology.

\section{INTRODUCTION}

Where technology is applied to the visualisation of historical monuments and ancient heritage sites the resulting images can present a view that is remote from the embodied experience of the visitor. While aerial photography, orthographic plans and digital virtual models can all be used to make visible aspects of a site that are not apparent from the ground, they do so at the cost of an increasingly distanced perspective. As the aerial artistphotographer Patricia Macdonald has put it:

On the one hand ... the comprehensive view can be a useful and inspiring vision ... On the other hand, however, the 'god-like view' available to mere mortals ... remains partial. It may be a dangerous delusion if the process of 'drawing back' results in a loss of human awareness of those things that may only be appreciated from close to, or when 'grounded' or 'immersed'. (Macdonald 2004)

Similar objectifying tendencies have been noted of digital visualisation technologies that 'reduce the past to a pattern of pixels, viewed on a screen of modern rationalism' (Thomas 2004: 201). Gillings (2002) maintains that while the adoption of digital virtual environments has been widespread in archaeology there are fundamental questions surrounding the meaning behind these methods that are yet to be addressed.
The history of digital imaging and the development of its visual vocabulary are still relatively short lived. As such it is not surprising that an understanding of its impact as an image-making medium remains underdeveloped. This paper will consider the creative use of digital imaging by drawing on a related visualisation technology with a much longer history. The view from above provided by aerial photography and also imagined elsewhere - such as in cartography - has had a profound impact on the way that we visualise the world, while forming an important part of archaeological practice. Debates surrounding the meaning and impact of the aerial view bear relevance to a range of emerging platforms for aerial imaging and digital visualisation, which tend to raise the observer to an elevated vantage point.

The first part of this paper will consider how virtual reality (VR) environments are currently used for spatial visualisation in archaeology and will go on to explore the discourse surrounding the significance of the aerial view. The second part will focus upon a case study where a practice-based research model was adopted to explore some of the challenges raised by the theoretical context. During this study the author's own creative practice in digital visualisation and aerial photography was employed to produce a time-based visualisation of the prehistoric Caterthun hillforts in Angus, Scotland. The steps taken to consider the visitor's embodied experience of the sites will be reflected 
upon and, finally, areas for further research and evaluation raised. A useful point of departure will be to consider the current use and meaning of visualisation technologies within a heritage context.

\section{VISUALISATION TECHNOLOGIES}

Cox (2006) defines visualisation as 'the process of making the invisible visible'. By these terms we can consider the role of aerial photography and digital visualisation technologies to be involved in the same pursuit, what Cox describes as the process of making the cognitive imagination visual using available and culturally dominant technologies'. In aerial archaeology, invisible features may only become visible from the air and under certain conditions such as oblique shadows or melting snow cover. An understanding of these naturally occurring phenomena has been exploited by what Hauser (2007: 164) describes as the 'typography of aerial archaeology', a toolkit still used as a primary method for discovery and interpretation of archaeological features (Bewley 2003). Recent advances in both remote sensing and digital image processing technologies have afforded new capacities for archaeological imaging on a landscape scale. The increased availability of lowcost remote aerial platforms and software solutions - such as structure from motion (SFM) photogrammetry - has led to a democratisation of aerial visualisation methods for archaeology (Verhoeven et al. 2012). These tools are primarily used for data visualisation, where a scientific process is followed in order to interrogate the archaeological record. Beyond this, spatial data can also be brought into an environment where archaeological interpretations and narratives can be visualised for the benefit of both experts and a lay public. These interpretative environments often host reconstructions of lost structures, and are usually discussed within archaeology under the term VR.

\section{OBSERVING VIRTUAL REALITY}

Where data-analysis environments such as GIS favour orthographic projection, VR affords the user a perspective view, one that can often be controlled through an interactive interface. The ambitions of VR - explicit in its title - look to the creation of virtual environments that imitate reality as closely as possible (Gillings, 2002).

How then are virtual spaces tested against the benchmark of the real? While the pursuit of 'photorealism' is often cited, the term risks mistaking the photograph for a 'transparent window', without taking into consideration the distinction between 'naturalism' and 'realism' in photography (Shanks 1997). Even where 'photorealism' is the ambition, facilitating the level of detail required remains a challenge for the realtime platforms preferred by VR. Instead, other criteria have been adopted to bring VR closer to reality. While to some degree spatial simulation can be scientifically verified - against real world measurements for example - our notion of what constitutes reality remains bound to embodied experience (Coyne 1999: 49). The connection between bodily engagement and the real is a critical premise of VR.

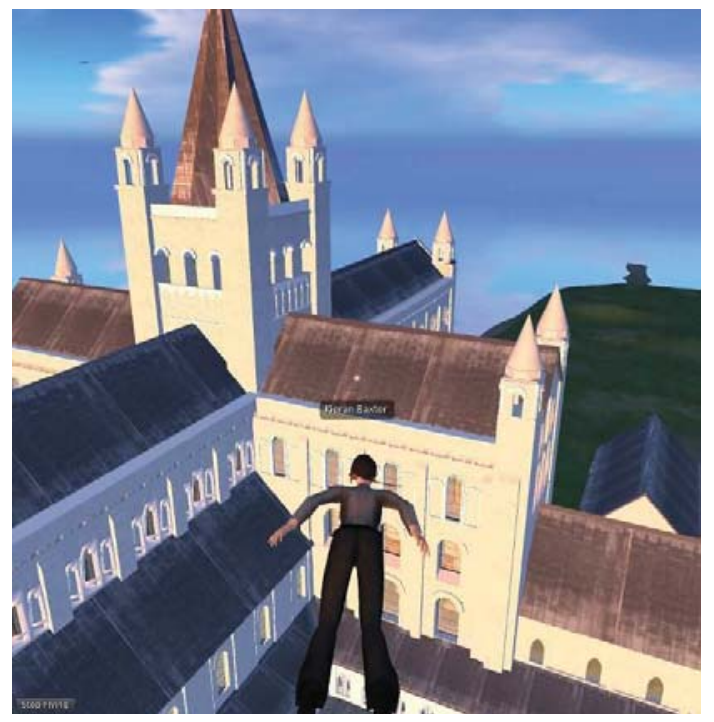

Figure 1: An avatar flying above a VR environment. Cathedral reconstruction by the Open Virtual Worlds group, University of St Andrews (C) (CC BY 3.0)

This is reflected where the observer is represented in the virtual environment as an avatar (figure 1), a digital 'proxy' (Kennedy et al. 2013) for the experience of the user. Beyond this the use of stereoscopic vision and head mounted displays attempts to further promote bodily engagement with the virtual world. Stereoscopic imagery draws attention to the bodily involvement of the observer, bringing subjectivity to what was historically regarded as the 'objective' technical image (Maxwell 2000, Saint-Amour 2003). Gurevitch (2012) argues that this dichotomy is already interrupted by the explicitly 'hand-crafted' - and therefore subjective - nature of computergenerated imagery, although it should be noted that so called 'mechanically reproduced images' have always been mediated by craft. Whether or not the myth of the objective image is sustained, the preoccupation of VR with bodily immersion points to an interest in furthering subjectivity and participation on the part of the user.

Attempts to ground the user bodily within the virtual world are sometimes at odds with the benefits of free movement in three-dimensional space. The presence of bodily flight and teleportation are reminders that VR remains a programmed 
environment where, despite attempts to emulate reality, basic physics can be subject to alteration (Slattery 2008). As such, the fly-through format effective at revealing three-dimensional structure at the cost of embodiment - has been questioned in terms of its suitability for archaeological visualisation (Gillings 2005). There is a pay-off here between a de-situated representation on one hand - where the user can jump to any point in or above the environment - and a more situated representation where the user is given a grounded point of view.

\section{SITUATING THE AERIAL VIEW}

Site plans, distribution maps and GIS are all methods of archaeological representation that provide a de-situated projection looking down upon the earth's surface. These mediums tend towards a mode of abstract Cartesian representation that is at odds with the phenomenological concerns expressed by some landscape archaeologists (Cummings et al. 2002, Brück 2005). Smyth (2014) maintains the opposition between Merleau-Ponty's existential phenomenology and the 'absolute perspective' represented by the writings of aerial reconnaissance pilot Saint-Exupéry, who is cited in Merleau-Ponty's works. Saint-Exupéry's (1940: 83) view that aviation 'unveiled for us the true face of the earth' demonstrates the optimism with which airborne technology was regarded - including within aerial archaeology - during the interwar period. This enthusiasm was replaced by shades of scepticism in the decades following World War II, in part due to the increasingly distanced and voyeuristic way in which aerial photography was subsequently used (Haffner 2013). Haffner outlines a relationship between increased altitude and a transition from the indigenous view to the gaze of an outsider. In a time when low altitude airspace is being opened up by the increased accessibility of remote-imaging platforms such as Unmanned Aerial Vehicles (UAVs) now may be an appropriate moment to reflect further on the meaning and impact of the aerial view in the context of its suitability for heritage visualisation.

While the high altitude perspective has been described as 'specular' (Thomas 1993: 25) - and aligned to a distinctly modern, rationalist mode of vision - this is juxtaposed with the holistic and ecological tendencies of the view from above (Cosgrove 2008: 89). Artist-photographers using aerial photography as a medium are often drawn to ecological themes. Emmet Gowin for example represents the surface of the earth as both a life system and the subject of human abuse in stark yet evocative images from the air (Williams 2002). Warner (2013) points to the paradoxical way in which the 'heroic' aerial view can at the same time offer a glimpse of 'personal' narratives. This dichotomy is reflected in the 'intimacy' (Goldberg 1991) evident in Marilyn Bridges' images of ancient monuments, taken from light aircraft flown at low altitudes. While the low altitude aerial view can certainly be described as a partially voyeuristic one (Fox 2009: 113), the airborne perspective does not always place the observer in the role of passive spectator. Bridges' aerial photographs reflect a sense of awe and wonder felt by the photographer, heightened by the viscerally intense experience of flight in a light aircraft (Bridges 1986).

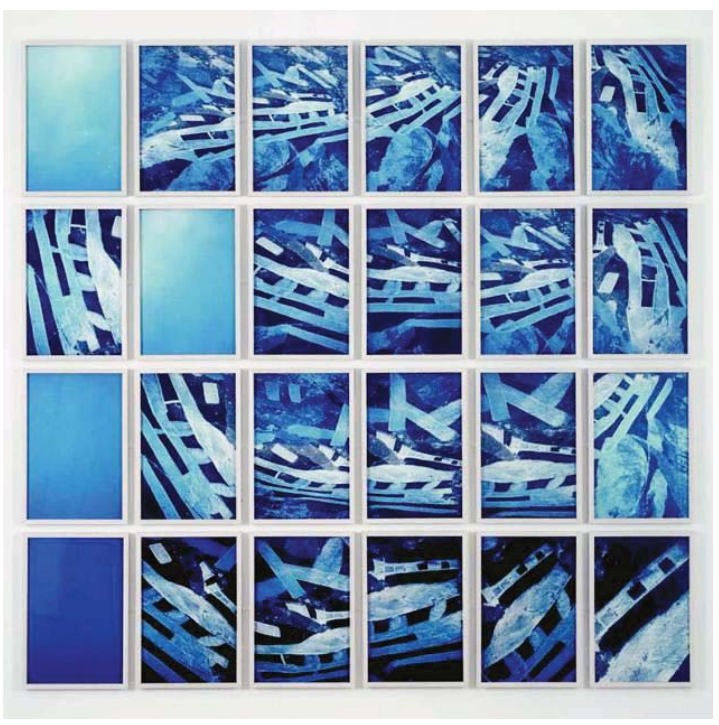

Figure 2: 'The Play Grounds Series, No 6: Burnt Moorland, Grouse Shooting', Patricia Macdonald in collaboration with Angus Macdonald (C) 1999

In this way the apparently commanding, 'god-like' nature of the aerial view uncomfortably accompanies the 'vulnerability' of the actual experience of flight (Macdonald 2004). Saint-Amour (2003) acknowledges that the distinct 'aesthetic' of each aerial platform has an effect on the 'context of aerial viewing' in the images produced. It is perhaps unsurprising that this aesthetic perception - as much associated with noise and movement as it is to vision - can become misinterpreted in static aerial photographs unless particular attention is paid to representing these aspects. Patricia Macdonald (2005a, b) for example uses creative practice to explore 'the meaning of viewpoint' - in several senses; literal, conceptual and metaphorical - in composite artworks consisting of multiple aerial photographs, made along paths of movement and sometimes juxtaposed with ground level views (figure 2). The work of Macdonald and others demonstrates a potential to re-associate the aerial view with the embodied experience - real or otherwise - of flight and its metaphors. While this relationship may be obscured in some manifestations of the aerial view, which tend towards cartographic practice, Castro (2013) 
maintains that 'sensation' remains a constituent component of aerial vision:

\begin{abstract}
The feeling of flight is as central to the aerial view as is the enjoyment experienced in observing the earth from an unusual point of view or of visually discovering and dominating it. (Castro 2013)
\end{abstract}

By suggesting that movement lends a 'kinaesthetic' aspect to aerial vision, Castro highlights the unexpected capacity for the aerial view to facilitate an immersive relationship with landscape that goes beyond spectatorship and dominance. On these terms the situation of the aerial view within the embodied experience of flight becomes an intriguing possibility.

\section{NAVIGATION AND MOVEMENT}

Our ability to read maps and aerial views has been attributed to a cognitive ability to imagine spaces from distant viewpoints, a function fundamental to successful navigation (Fox 2009, Cosgrove \& Fox 2010). Ingold (2000) argues that the non-indexical map has little to do with the insider's knowledge of a given terrain. Rather than requiring an imagined aerial view, Ingold maintains that the environment is perceived as the culmination of observations made as we move throughout it:

\begin{abstract}
Life on the spot surely cannot yield an experience of place, of being somewhere. To be a place, every somewhere must lie on one or several paths of movement to and from places elsewhere. (Ingold 2007)
\end{abstract}

A concern for the way that landscape is perceived through human agency has had a marked impact upon the study of prehistory since the mid 1990s, when a range of 'phenomenological' approaches became established within British archaeology (Brück 2005). By prioritising lived experience in the interpretation of ancient monuments archaeologists have paid increasing attention to the movement of people through the landscape and the 'aesthetic qualities' such journeys may reveal (Watson 2001). The qualitative - even ineffable - nature of this kind of interpretation has been frustrated by the limitations of traditional site recording, leading to a reconsideration of the methods employed by field archaeology.

\section{CREATIVE PRACTICE AND ARCHAEOLOGY}

Archaeologists have explored a number of more creative approaches to field recording in an attempt to counter the 'abstract totalization of traditional cartography' (Brück 2005). Drawing inspiration from land artists and sculptors who have worked in the landscape, Tilley et al. (2000) proposed a form of 'archaeological artistic practice' that is equipped to tackle experiential and aesthetic elements of ancient heritage from an archaeologically informed stance. Tilley et al. acknowledge the need for such work to be 'theoretically informed', emphasising the importance of their experience in archaeological practice. The resulting artworks present a rethinking of space and place from an experiential perspective, albeit without the well-defined aesthetic vocabulary that might result from a more sustained art practice.

The dialectic nature of art in the context of archaeological enquiry has been, until recently, largely neglected in art history (Moser \& Smiles 2005). If the areas between disciplines are to be explored then close consideration must be given to how visual language is interpreted within different contexts. Interdisciplinary collaboration is one platform for such dialogues to take place. Those who engage in practice across different fields are well positioned to reflect on the contribution that creative practice can make to archaeology.

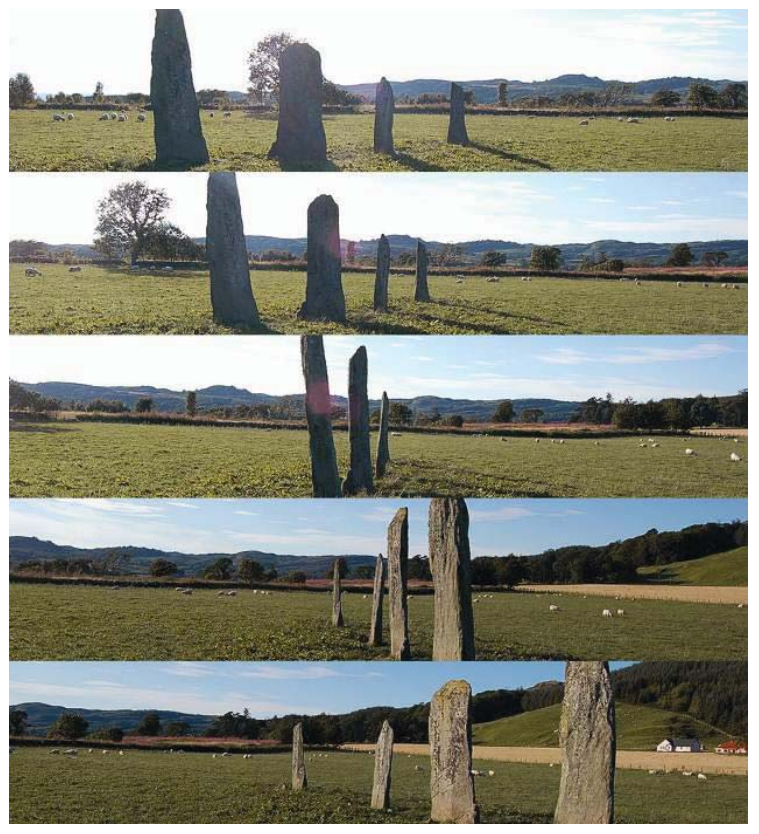

Figure 3: Frames from a 'Trans-scape' animation of Ballymeanoch standing stones, Aaron Watson (c) 2008

Watson (2008) suggests that an artistic response can supplement traditional site recording methods by introducing more personal perspectives. Using sustained creative practice in photography and other media, coupled with archaeological practice, Watson $(2008,2009)$ presents an alternative view that visualises the importance of movement and embodiment in the interpretation of archaeological landscapes (figure 3). Such approaches to creative practice move away from the totalising modes of vision that have tied archaeological representation to a distinctly modern paradigm (Thomas 2004). 


\section{PUTTING THEORY INTO PRACTICE}

The author has adopted a practice-based research model in order to further explore the role of creative practice in bridging the gap between visualisation technologies and the visitor's experience of built heritage. This creative practice draws from a background in animation and digital media as well as experience in low altitude aerial photography, primarily using the technique of Kite Aerial Photography (KAP). To produce time-based digital visualisation outcomes, SFM photogrammetry is used to generate three-dimensional structural data from sequences of aerial photographs. This particular combination of methods has proved well suited for the purpose of archaeological recording and interpretation (Verhoeven et al. 2012). The intent here is not to generate data for analysis however but to use gathered material to create interpretative visualisations that are suitable for consumption by a lay audience.

The outcomes aim to enhance the visitor's experience of built heritage sites by placing archaeological interpretations within a virtual environment that is closer to an embodied experience of place. While this audience may extend to potential visitors who are unable to experience a site in person, remote access is not the primary focus here. Instead an attempt will be made to connect the embodied experience of visiting a site with the disembodied yet revealing perspectives provided by aerial imaging and digital visualisation technologies. The second part of this paper will focus on a case study that was designed to raise the challenges outlined here and attempts to address them through creative practice.

\section{THE CATERTHUN HILLFORTS CASE STUDY}

White and Brown Caterthun are two prehistoric hillforts situated on neighbouring hilltops on the periphery of the Grampian Mountains in Angus, Scotland (figure 4). This location was chosen for the case study because it posed a number of challenges in visualising a complex and multifaceted pair of associated sites. Archaeological features range from an artefact scale - such as the cup-marked boulder on the northwest slope of White Caterthun - to large yet subtle outer earthworks that only become self evident from high altitude. The site is a popular destination for walkers and the aesthetic experience of ascending to the summit of the hillforts not only defines the character of the current day environment but is also a key consideration in the interpretation of the monuments. While high altitude aerial photographs reveal many of the features that make up the sites, these images can give little insight into the microcosm of the sites themselves in the context of the dynamic landscape of which they form part.

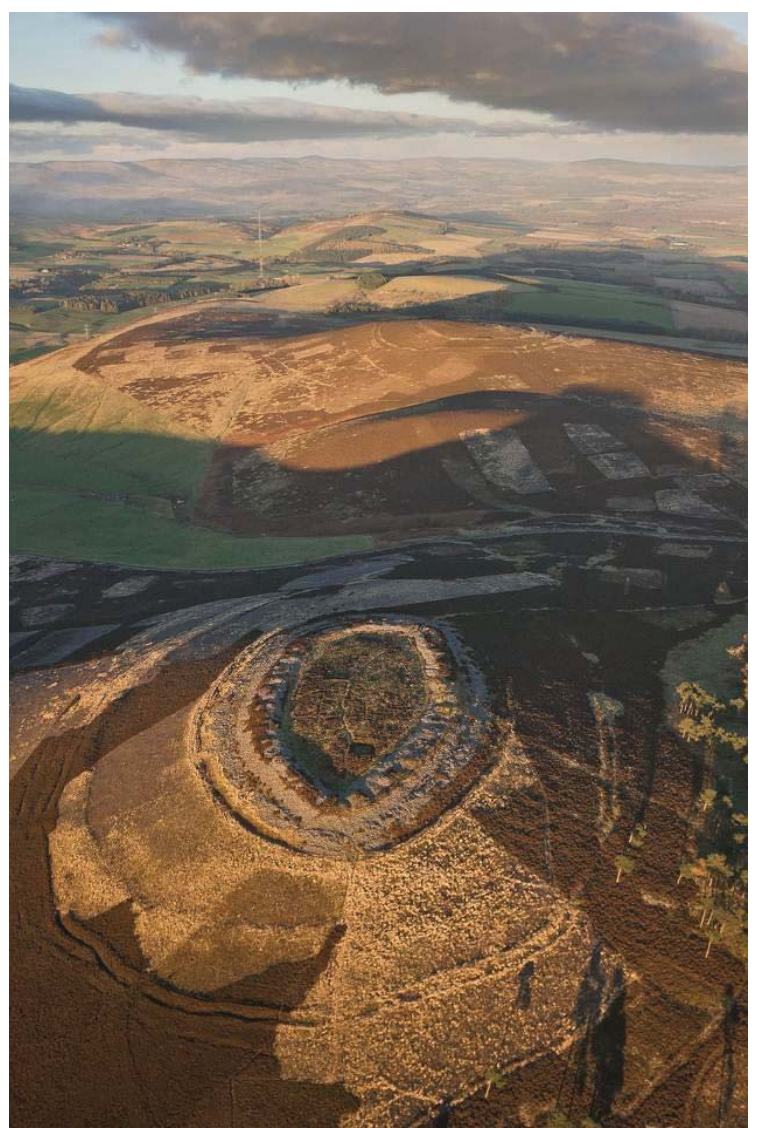

Figure 4: A high altitude view of the Caterthun hillforts. Photograph (c) Kieran Baxter (CC BY-NC-SA 3.0)

\section{FIELDWORK AND PHOTOGRAPHY}

The process of visualising the Caterthuns was premised on fieldwork, during which time was spent gathering visual material and gaining a tacit familiarity with the sites. This fieldwork was facilitated in part by support from Historic Scotland, as well as the co-operation of the landowner. Sequences of photographs were gathered using KAP at altitudes of up to around 50 meters, while higher altitude photographs - from above around 300 meters - were taken during a fly-over in a light aircraft. In addition to the aerial photography work live action footage was filmed from the ground and using a tracking dolly and jib, which allowed elevation to around two meters height. While the imagery being gathered was in part informed by a pre-planned outline of the intended outcome, much of the photographic decision-making was made onsite. In this way the imagery was influenced not only by the conditions at the time of shooting but also by the experiences of the photographer. Using KAP requires the operator to engage with the site at ground level while considering the view from above. It is hoped that this process of embodied 
engagement resulted in a better-informed photographic treatment of the site.

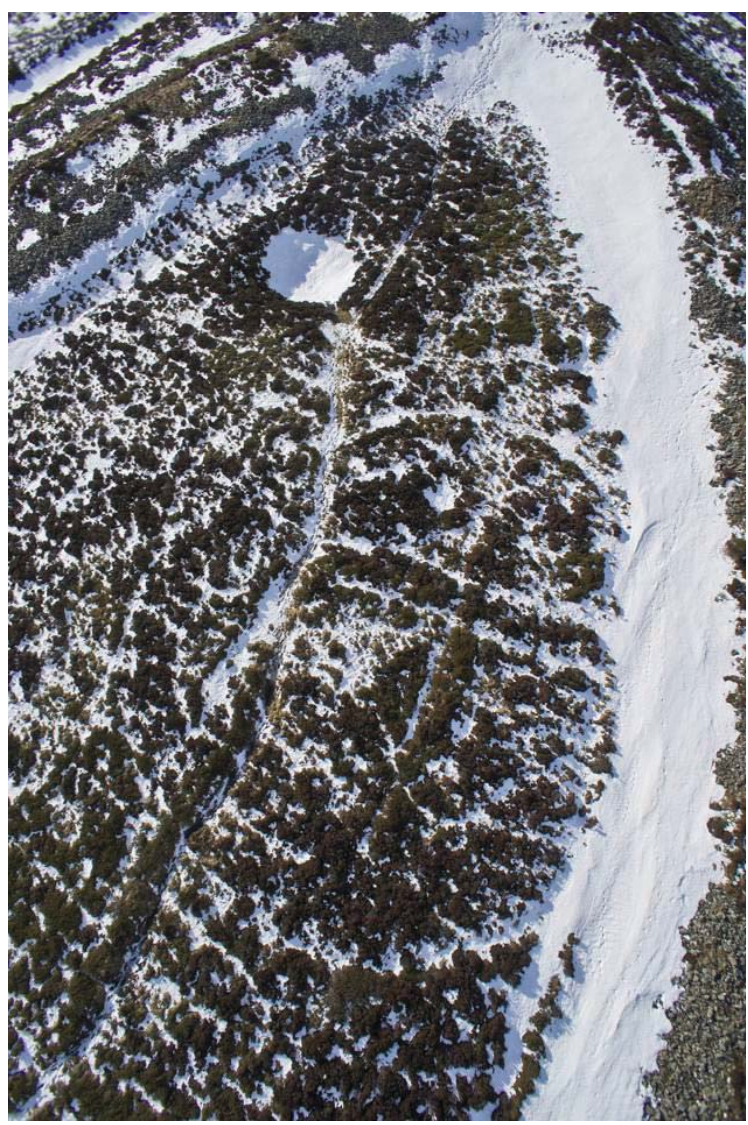

Figure 5: Ephemeral enclosure remains visible beneath melting snow cover in this kite aerial photograph. Photograph (c) Kieran Baxter (CC BY-NC-SA 3.0)

Seasonal change and weather conditions were carefully considered during the fieldwork. Visits to the site were made during different times of day and year in order to record a range of lighting conditions as well as varying snow cover. Images taken under certain conditions served to reveal particular archaeological features. Figure 5 for example shows a circular enclosure of unknown date in the centre of White Caterthun, made visible by melting snow. While these subtle features could be later revealed using the derivative SFM data it was considered that using natural conditions where possible was a more suitable approach in this case, as such images can be better related to visual experience. In order to maintain this fidelity to the photographic appearance of the site, real world lighting conditions were used in place of artificially generated virtual lights. Early morning and evening light was used to show up the topography and also reflect the sense of atmosphere that was evoked by spending time on site. It was considered that the Caterthuns could not be properly represented in a single, static virtual model but that steps might be taken to creatively respond to the dynamic and ephemeral nature of the place. To achieve this a number of different types of imagery were combined to inform the final outcome.

\section{FROM PHOTOGRAPHY TO VIRTUAL SPACE}

The gathered photographic material was processed using the SFM photogrammetry software Agisoft PhotoScan in order to resolve the two-dimensional imagery into three-dimensional space. Two main approaches, using the same tools, were adopted to do this. Some sequences - taken from high altitude - were chosen to allow for the most complete and consistent coverage possible for both hillfort sites. These models - processed in collaboration with Susie Green, UCL - allowed for the most flexibility within the virtual environment. Here the observer could be placed retrospectively in any position above the sites as long as a high altitude camera position was maintained. This method was valuable in showing the overall structure and relationship between widespread archaeological features. In terms of the issues raised in the first part of this paper however, this method alone was found to be limiting.

By contrast the low altitude photographic sequences were not taken with total coverage in mind but rather with respect to particular camera angles that were found to be both compositionally useful and appealing. These static images could then be processed into three-dimensions to allow a virtual camera to be animated along a path of movement, restricted to the approximate area of the original camera positions. These cameraspecific segments could be combined to create more ambitious camera paths that related to a series of original photographs. In contrast to the total-coverage approach this method prioritises photographic composition in the field.

\section{THE TIME-BASED OUTCOME}

Once the gathered material was processed into a three-dimensional environment, a series of animated camera paths were defined with the aim of revealing different aspects of the site through a continuous narrative. The resulting time-based outcome introduces the site first from a grounded perspective, the view that the visitor is most likely to relate to. While this perspective gives an impression of the embodied experience of place at the Caterthuns there is a limit to how much of the site's archaeological interpretation can be shown in this way. To reveal these aspects of the site, the camera then follows a path of movement that passes through low altitude and high altitude aerial perspectives (figure 6).

It is believed that the layering of these different modes of observation serves to build up a more 
comprehensive impression of the site. Thus when the camera flies over the hillforts from high altitude to reveal elements of the archaeological interpretation there is the possibility for this view to be seen in the context of embodied movement over the site, rather than a disembodied view over an explicitly virtual environment.

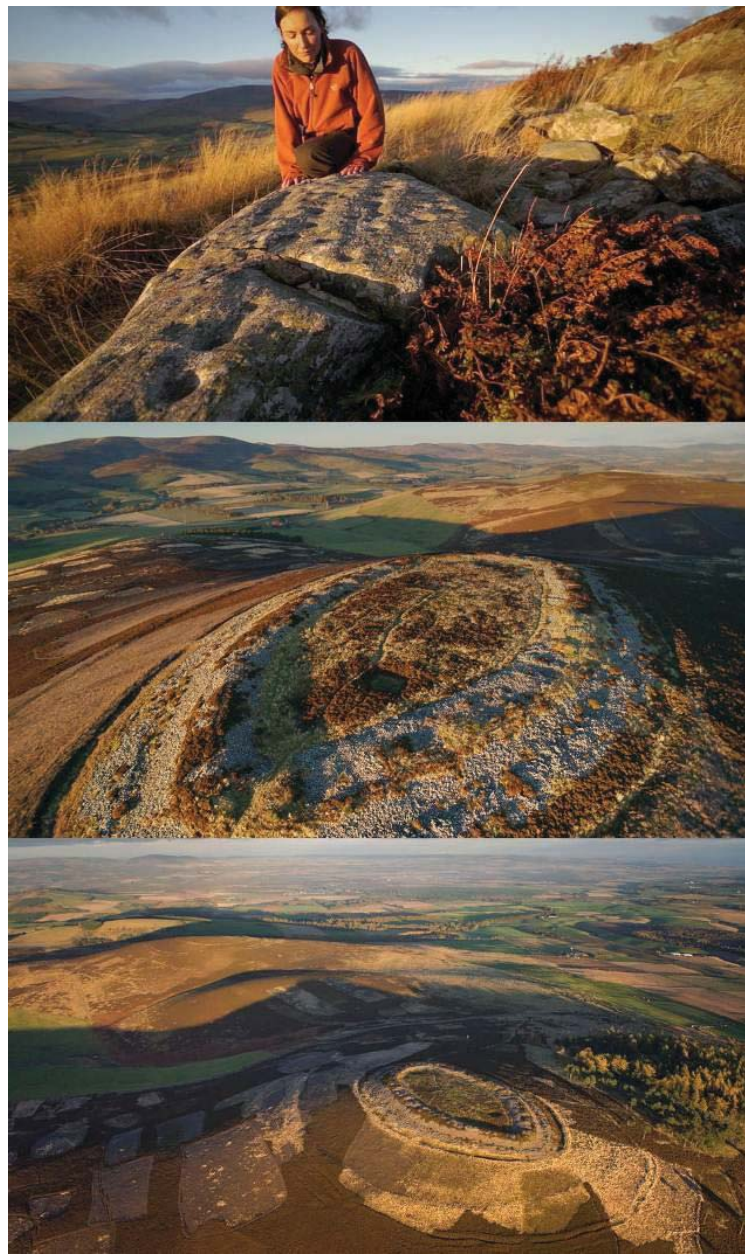

Figure 6: Moving from the microcosm to the macrocosm at White Caterthun. (c) Kieran Baxter (CC BY-NC-SA 3.0)

\section{CONCLUSION}

It is not suggested that visualisation can act as a surrogate to embodied experience, not least of all because the realm of vision is only one aspect of multisensory experience (Thomas 2008). Instead the case study described here aims to move away from static and totalising representations of space by introducing alternative perspectives, movement and flux into the visual language of digital visualisation. This is implemented by layering grounded and aerial views, considering the changing conditions on site, and prioritising photographic composition that is informed by experience in the field. Further work is required to evaluate these outcomes with both professional stakeholders and a lay audience in mind. It is hoped that such a multi-layered outcome can better reflect the multifaceted nature of the site and can be more easily related to the embodied experience of the visitor.

\section{ACKNOWLEDGEMENTS}

This paper was completed during the author's doctoral research at Duncan of Jordanstone College of Art and Design, University of Dundee. This PhD is supported by the AHRC and DJCAD, and supervised by Prof Nigel Johnson and Dr Chris Rowland. Thanks are due to Dr. Patricia Macdonald, Dr. Aaron Watson and Dr. Alice Watterson for valuable input and critique during the writing of this paper. Fieldwork was facilitated by generous support from Historic Scotland and the kind co-operation of Balnamoon Estate. During the fieldwork, Kieran Duncan, Michael Webster and Nuria Valdeon kindly volunteered practical assistance. For additional help and advice, thanks are also due to James Carnegy, Ronnie Cowan, Susie Green, Kit Reid and Richard Strachan.

\section{REFERENCES}

Bewley, R. (2003) Aerial Survey for Archaeology. Photogrammetric Record 18(104): 273-292.

Bridges, M. (1986) Markings: Aerial Views of Sacred Landscapes. New York, Aperture.

Brück, J. (2005) Experiencing the past? The development of a phenomenological archaeology in British prehistory. Archaeological Dialogues 12(01): 45-72.

Castro, T. (2013) Aerial Views and Cinematism, 1898-1939. Seeing From Above: The Aerial View in Visual Culture. M. Dorrian and F. Pousin. London, I.B. Tauris 118-133.

Cosgrove, D. (2008) Geography \& Vision: Seeing, Imagining and Representing the World. London, I. B. Tauris

Cosgrove, D. and Fox, W. L. (2010) Photography and Flight. London, Reaktion Books Ltd.

Cox, D. (2006) Metaphoric Mappings: The Art of Visualization. Aesthetic Computing. P. A. Fishwick. Cambridge, MIT Press: 89-114.

Coyne, R. (1999) Technoromanticism: Digital Narrative, Holism and the Romance of the Real. Cambridge, MIT.

Cummings, V., Jones, A. and Watson, A. (2002) Divided Places: Phenomenology and Asymmetry in the Monuments of the Black Mountains, Southeast Wales. Cambridge Archaeological Journal 12(1): 57-70.

Fox, W. L. (2009) Aeriality: on the world from above. Berkeley, Counterpoint. 
Gillings, M. (2002) Virtual Archaeologies and the Hyper-Real. Virtual Reality in Geography. P. Fisher \& D. Unwin (Vol. 17-32). London \& New York: Taylor and Francis.

Gillings, M. (2005) The Real, the Virtually Real, and the Hyperreal: The Role of VR in Archaeology. Envisioning the Past: Archaeology and the Image. S. Smiles and S. Moser. Oxford, Blackwell: 223239.

Goldberg, V. (1991) An Intimacy with the Land: The Aerial Photography of Marilyn Bridges. Archaeology 44: 32-39.

Gurevitch, L. (2012) The Birth of a Stereoscopic nation: Hollywood, Digital Empire and the Cybernetic Attraction. Animation: An Interdisciplinary Journal 7(3): 239-258.

Haffner, J. (2013) The View from Above: The Science of Social Space. London, The MIT Press.

Hauser, K. (2007) Shadow Sites: Photography, Archaeology, and the British Landscape. Oxford, Oxford University Press.

Ingold, T. (2000) The Perception of the Environment. Oxon, Routledge.

Ingold, T. (2007) Lines: A Brief History. Oxon, Routledge.

Kennedy, S., Fawcett, R., Miller, A., Sweetman, R. J., Dow, L., Campbell, A., Oliver, I., McCaffery, J. and Allison, C. (2013) Exploring Canons and Cathedrals with Open Virtual Worlds: The Recreation of St Andrews Cathedral, St Andrews Day, 1318. IEEE, Digital Heritage International Congress 2013, Marseille, France.

Macdonald, P. and Stevenson, S. (2004) Patricia Macdonald in conversation with Sara Stevenson. History of Photography 28: 43-56.

Macdonald, P. (2005a) Conceptual Landscapes: The Aerial Photographs of Patricia Macdonald. The Oxford Companion to the Photograph. Lenman, R. Oxford, Oxford University Press: 9 and opp. 42-43.

Macdonald, P. (2005b) Emergent Landscapes. Journal of Visual Art Practice 4(2-3): 83-96.

Maxwell, A. (2000) Colonial Photography and Exhibitions: Representations of the Native and the Making of European Identities. London, Leicester University Press.

Moser, S. and Smiles, S. (2005) Introduction: The Image in Question. Envisioning the Past: Archaeology and the Image. S. Smiles and S. Moser. Oxford, Blackwell: 1-12.
Saint-Amour, P. (2003) Modernist Reconnaissance. Modernism/Modernity 10(2): 349-380.

Saint-Exupéry, A. (1940) Wind, Sand and Stars. London, The Windmill Press.

Shanks, M. (1997) Photography and Archaeology. The Cultural Life of Images: Visual Representation in Archaeology. B. L. MolyNeaux. Abingdon, Routledge: 73-107.

Slattery, D. (2008) VR and hallucination: a technoetic perspective. Technoetic Arts: A Journal of Speculative Research 6(1).

Smyth, B. (2014) Merleau-Ponty's Existential Phenomenology and the Realization of Philosophy. London, Bloomsbury.

Thomas, J. (1993) The Politics of Vision and the Archaeologies of Landscape. Landscape: Politics and Perspectives. B. Bender. Oxford, Berg: 19-48.

Thomas, J. (2004) Archaeology and Modernity. Oxon, Routledge.

Thomas, J. (2008) On the ocularcentrism of archaeology. Archaeology and the Politics of Vision in a Post-Modern Context. J. Thomas and V. Jorge. Newcastle upon Tyne, Cambridge Scholars Publishing.

Tilley, C., Hamilton, S. and Bender, B. (2000) Art and the Re-Presentation of the Past. The Journal of the Royal Anthropological Institute 6(1): 35-62.

Verhoeven, G., Taelman, D. and Vermeulen, F. (2012) Computer Vision-Based Orthophoto Mapping of Complex Archaeological Sites: The Ancient Quarry of Pitaranha (Portugal-Spain). Archaeometry 54(6): 1114-1129.

Warner, M. (2013) Intimate Communiqués: Melchior Lorck's Flying Tortoise. Seeing From Above: The Aerial View in Visual Culture. M. Dorrian and F. Pousin. London, I.B. Tauris: 11-25.

Watson, A. (2001) Composing Avebury. World Archaeology 33(2): 296-314.

Watson, A. (2008) Learning to see through the 'Kilmartin Eye'. Archaeology and the Politics of Vision in a Post-Modern Context. J. Thomas and V. Jorge. Newcastle upon Tyne, Cambridge Scholars Publishing: 147-162.

Watson, A. (2009) Carneddau: Stone. Materialitas: working stone, carving identity. B. O'Connor, G. Cooney and J. Chapman. Prehistoric Society Research Paper 3. Oxford, Oxbow: 75-92.

Williams, T. (2002) The Earth Stares Back. Emmet Gowin: Changing the Earth. J. Reynolds. London, Yale University Press: 125-131. 